This is an accepted manuscript of an article published by Taylor \& Francis in Journal of Social Service Research on 8 Nov 2018, available online: https://doi.org/10.1080/01488376.2018.1524813

\title{
Ethical Dilemmas and Areas of Social Work Intervention in Spain
}

\author{
Juan-Jesús Viscarret, Francisco Idareta, Alberto Ballestero, and María-Jesús Úriz \\ Department of Social Work, Public University of Navarre, Navarre, Spain
}

ORCID
Juan-Jesús Viscarret
http://orcid.org/0000-0001-6867-7294
Francisco Idareta
$\frac{\text { http://orcid.org/0000-0003-0325-5298 }}{\text { Alberto Ballestero }}$
$\frac{\text { http://orcid.org/0000-0002-7946-761X }}{\text { María-Jesús Úriz }}$
http://orcid.org/0000-0002-8169-3173

CONTACT

Alberto Ballestero: alberto.ballestero@unavarra.es Department of Social Work, Public University of Navarre, Campus de Arrosadia, 31006 Pamplona, Navarre, Spain.

To cite this article: Juan-Jesús Viscarret, Francisco Idareta, Alberto Ballestero \& María-Jesús Úriz (2019): Ethical Dilemmas and Areas of Social Work Intervention in Spain, Journal of Social Service Research, doi: 10.1080/01488376.2018.1524813 


\title{
Ethical Dilemmas and Areas of Social Work Intervention in Spain
}

\begin{abstract}
The purpose of this study is to identify the types of ethical dilemmas that Spanish social workers face in their respective areas of intervention. The intervention areas that have been studied are health, children, immigrants, women, family, marginalized persons, ethnic minorities, young people, prisoners, elderly people, refugees and asylum seekers, schools and social and employment-related integration, mental health, disability and drug addictions. A quantitative methodology was chosen using a version of the questionnaire prepared by Eileen J. Ain in a sample of 700 Spanish social workers. The statistical analysis shows the correlation between the different areas of intervention in Social Work and the most significant ethical dilemmas that such professionals have to solve. The most pertinent ethical dilemmas are found in the healthcare sector (confidentiality, disclosure of personal information and patient autonomy). The article is an important contribution for Social Work at the national level that emphasizes the importance of the ethics of Social Work in social interventions. It is proposed to deepen the investigation of each of the areas of intervention for future research, as well as to carry out comparative studies between different countries.
\end{abstract}

\section{Keywords}

Social intervention; social work ethics; ethical dilemmas; ethical decision making; Spain

\section{Introduction}

Professional ethics is much more than a mere prolongation of individual morality and, within the professional context, it is not enough to simply act according to one's own individual moral values. For some time, now more and more importance has been given to the correlation between the various professional problems and certain ethical dilemmas. 
In medicine and nursing, there are some studies which emphasize the importance of providing medical professionals and nurses with strategies for the analysis and resolution of ethical dilemmas in order to anticipate and reduce the level of stress generated within the working environment (Corley, Minick, Elswick \& Jacobs, 2005; Hofmeyer, 2003; Førde \& Aasland, 2008; Häggström, Mbusa \& Wadensten, 2008; Rathert, May \& Chung, 2016; Rushton, Kaszniak \& Halifax, 2013; Wadensten, Wenneberg, Silén, Tang \& Ahlström, 2008).

The work setting is a fundamental variable in the study of ethical dilemmas (Ballestero, Úriz $\&$ Viscarret, 2012). Some studies have pointed out the existing relationship between the malpractice of professionals and the ethical climate in the organization (Appelbaum, Deguire \& Lay, 2005), as well as the existing negative correlation between a stressful working environment and moral sensitivity (Bégat, Ellefsen \& Severinsson, 2005).

However, no studies have been undertaken to identify the ethical dilemmas that emerge in the different work settings: medicine, nursing, social work, etc. In regards to social work and, if research is restricted to the national level, the scarce investigations carried out have established different typologies of ethical behavior in social intervention and have categorized the different roles into four occupational profiles (Ballestero, Úriz, \& Viscarret, 2013; Ballestero, Viscarret, \& Úriz, 2013).

It is known what types of ethical behavior can be observed in professional social work interventions and what occupational profiles these professionals of social intervention have, however, it is not yet known whether there is a correlation between their respective areas of targeted intervention and the ethical dilemmas they face there. The objective is to identify the different ethical dilemmas facing social workers in their daily professional activities and demonstrate whether there are any significant differences depending on the occupational area in 
which they work. The initial hypothesis is that significant differences will be observed in relation to these ethical dilemmas depending on the occupational area, thus proving the existence of a correlation between a certain occupational activity and ethical dilemmas. The second hypothesis is that some ethical dilemmas appear transversally in the different professional areas of Social Work, but with different relevance.

\section{Areas of Social Work Intervention}

The areas of professional social work intervention have been developed in each country in a different manner based on their own historical and social evolution. In the majority of western countries, professional intervention of this kind has developed from being generalist in character to an increasingly specialized form of intervention. By exploring the activities carried out by social workers over the years since the emergence of this profession, one can see the dynamism and the vitality of a profession in a continuous change and progression, the limits of which are at times blurry given that this type of activity has been expansive in character in regards to the areas in which it has developed.

Some publications refer to areas of social work which may be of surprise to the professionals in the practice in Spain, such as Veterinary Social Work or Military Social Work (Dulmus \& Sowers, 2012). In Spain, the Libro Blanco del Trabajo Social (White book of social work) recognizes the appearance of new spaces for professional development (Vázquez, 2005). Social workers can be found in multiple and diverse social entities and there are always at least four factors which interact with each other: legislation, the type of organizations created, the target population and the type of problems and needs covered and attended to. It makes it difficult to talk about the practice of social work without considering the context in which the job occupational activities are carried out. 
Human behavior cannot be understood without taking into regard the context in which it is produced. Likewise, occupational practices cannot be understood without considering the area in which they are developed. Ethical behavior is no different and is therefore an inherently interesting space for further investigation. The initial hypothesis is that the occupational area in which social workers intervene may predetermine the type of ethical dilemmas they face. Should this hypothesis be confirmed, ethics training could be directed or focused better to help social workers to understand, reflect and act accordingly when they find themselves in situations of ethical conflict.

In Spain, the specification of the areas of social work intervention is born of political and legislative developments in the country which have led to the regulation and implementation of these changes to Social Services. The various political changes in the country and the legislation related to Social Services have regulated the specification of the social worker's profile and their areas of intervention.

Over the course of the last few years, Social Work legislation has been passed which the Public System of Social Services has ratified in the Autonomous Communities, providing people and certain groups with the resources, initiatives and provisions needed for their full development. Besides this, the prevention, treatment and elimination of the causes of marginalization have been addressed. On the other hand, certain services and provisions have been identified in the portfolios of the Autonomous Communities which must be guaranteed by the Public System of Social Services in relation to homeless people. These provisions are provided through the Municipal Social Services that make up the Primary Level of Care and Insertion. Primary care includes emergency social programs and care provided to groups with 
specific social problems. In accordance with the majority of these laws, social services are structured on two levels: General Social Services and Specialized Social Services.

These services are organized and managed in regards to the sections of the population at which they are aimed. The following factors are taken into account, without forgetting the previous contributions of other researchers: health (Goldman \& Tabak, 2010; Greene \& Kulper, 1990; Kadushin, 2001; Proctor, Morrow-Howell \& Lott, 1993; Sparks, 2006), childhood (Meysen \& Kelly, 2018), immigrants (Furman, Ackerman, Loya, Jones \& Egi, 2012; Mänttarivan der Kuip, 2016), women (Cervantes, 1993; Lindhorst, Macy \& Nurius, 2005; Wiech, 2009), family (Handon, 2009), homeless (Banks, 2011; Spijkerboer, van der Stel, Widdershoven \& Molewijk, 2017), ethnic minorities (Pergert, Ekblad, Enskär \& Biörk, 2008; Van Keer, Deschepper, Francke, Huyghens \& Bilsen, 2015), youth (Banks, 2012), prisoners (Baldry \& Sotiri, 2009; Toi, 2015), the elderly (Bergeron \& Gray, 2003; Fitting, 1986; Smebye, Kirkevold \& Engedal, 2016), refugees (Barrero, 1993; Hayes \& Humphries, 2004), educational centres (Allen-Meares, 2004; Constable, 2002; Dupper, 2003; Openshaw, 2008; Reamer, 2003; Roberts, 1971; Villarreal, 2017), mental health (Molewijk, Hem \& Pedersen, 2015), disability (Donat, 2005; Iacono \& Murray, 2003; Wilkins, 2012), and drugs (Galvani \& Forrester, 2011), among others, who find themselves marginalized or in situations of need. Throughout the investigation, we will answer this question: what ethical dilemmas do Spanish social workers find in their daily work according to their area of social intervention?

\section{Method}

\section{Sample}

Seven hundred Spanish social workers participated in the survey, because the objective of the study was to know the vision of Spanish social work professionals. The data matrix is made up 
of a sample of 700 social workers. The sample unit is random and nominative. By applying the sampling error formula for finite populations, the confidence level of the two Sigma (95.5\%), where $p=q=0.50$, where the reference universe is 8505 professionals and the sample obtained is $N=700$, the sampling error is $\pm 3.5 \%$.

The gender distribution of the sample is highly feminized, as in other recent investigations (Gómez, Alonso, \& Llamazares, 2018). Ninety-one percent are women and 9\% are men. In regards to the age distribution, $40 \%$ are between 31 and 40 years of age and $30 \%$ are between 41 and 50 , while $17 \%$ are between 20 and 30 and only $13 \%$ are over 50 . Seventy percent fall into the range of 31 to 50 years of age.

In terms of professional experience, $38 \%$ have been in the profession for between 6 and 15 years, $28 \%$ between 16 and 25 years, $24 \%$ for up to and including 5 years and only $10 \%$ have more than 25 years of experience. In relation to the place of work, the vast majority (70\%) work in public administrations, $14 \%$ work for private entities and $12 \%$ in combined entities. Of those remaining, $1 \%$ are unemployed, $1 \%$ are self-employed and $2 \%$ currently work in another sector.

In regards to areas of intervention, the sample was distributed as follows: family $(16 \%)$, elderly people (13\%), disabled people (11\%), women (10\%), children (9\%), immigrants (7\%), health centers and hospitals $(6 \%)$, adolescents and young people $(6 \%)$, ethnic minorities $(5 \%)$, mental health (5\%), drug dependency (4\%), educational centers and socio-labor integration (4\%), homeless people (3\%), prisoners and former prisoners (1\%) and refugees and asylum seekers $(1 \%)$.

The ethical dilemmas which emerge in the abovementioned fifteen areas of intervention have been considered. The independency test (Chi squared) was used to establish a correlation and association between the two qualitative variables: the area of intervention in which the social 
workers work (YES/NO) and the ethical dilemmas (YES/NO). The following null hypothesis (H0) is proposed: at the time of emergence of a particular ethical dilemma, there are no significant differences between those who carry out their occupational activities in a certain professional area and those who do not. The assigned confidence level is $95 \%$, assuming a sampling error of 5\%, that being, $p<0.05$ (significant), $p<0.01$ (very significant) $*$ and $p<$ 0.001 (highly significant) **.

\section{Instrument}

The only questionnaire used is based on the one elaborated by Dr Ain (2003), which was reviewed and approved by Dr Philip J. Boyle, associate director of the Hastings Institute (Vancouver, Canada), Vice President and editor in chief of the Park Ridge Centre (Chicago, Illinois); Jonathan D. Moreno, professor of bioethics at the University of Virginia and director of the Center for Bioethics and Barbara Ann Liberman, expert in statistics and programmer analyst of the Ministry of Health and Social Services of the United States of America. Besides this, the questionnaire was submitted for evaluation before a tribunal of experts: Dr Norman Linzer and Dr Charles Auerbach, professors of social work at Yeshiva University (New York) and Elaine Congress, professor of social services and post-graduate and doctorate program director at Fordham University (New York).

The questionnaire was translated, localized and adapted to the Spanish context by the Efimec Group of the Public University of Navarra (Úriz, Ballestero \& Urien, 2007) and is divided into seven main blocks: personal data, professional data, code of ethics, ethical questions, ethical dilemmas, ethical dilemmas in the work setting and training in ethics. The questions related to the areas of occupational intervention (18 items) have been used as well as those related to the 
ethical dilemmas faced (18 items). The survey was made up of closed questions accompanied by a Likert scale of four options (Never, Rarely, Sometimes and Quite Often).

\section{Procedure}

The methodology used was quantitative using a questionnaire sent through postal mail. A return envelope and a cover letter that assured confidentiality and anonymity accompanied the survey that was sent to 8505 members of the General Council of Social Work.

The return rate was 20\% [1523 usable questionnaires/7963 questionnaires sent (discounting those returned to us) $* 100$ ] of the total number of usable questionnaires, a process of evaluation and filtering the data was undertaken in order to guarantee the quality of the information obtained (searching for inconsistencies, evaluating the questions left unanswered...), which gave the final sample needed for the study. Next, we proceeded to enter the data in the computer and perform the statistical analysis.

\section{Data Analysis}

The statistical analysis was carried out using the program SPSS, v.21 (SPSS, Chicago, IL), through a statistical contrast $\chi^{2}$ (Chi square), which is used to identify dependency relationships between qualitative variables and allows to confirm with a certain level of confidence whether the level of one qualitative variable influences the level of the other nominal variable under analysis. In this case, it is observed whether the professional area in which a certain social worker works influences the type of ethical dilemma they face.

\section{Ethic Statement}

The current study conforms to the internationally accepted Ethics in research with human participants of the American Psychological Association (Sales \& Folkman, 2000). Participants were informed that their answers would be processed and reported anonymously; it was stated 
that, by completing the questionnaire, the participants provided consent for using their information for the research. Given the nature of the study (e.g. no deception, no hazards or discomforts, no confidential information required, etc.), no specific approval from the ethics committee needed to be sought.

\section{Results}

The objective of this study was to find the answer to this question: what ethical dilemmas do Spanish social workers find in their daily work according to their area of social intervention? Let's see the results obtained in each of the areas of social intervention and the ethical dilemmas that appear in them.

The first hypothesis affirmed that the ethical dilemmas found in each of the areas of intervention will depend on the area and not on the work itself. The second hypothesis said that some ethical dilemmas will be transversal and will appear to a greater or lesser extent and with different relevance in more than one area of intervention.

The results provided (see Table 1) are related to the main areas of intervention where the null hypothesis of no correlation or of independence has been rejected. In other words, it can be seen that these areas of intervention confirm, with a probability of error of $5 \%$, that there is a correlation between the area of intervention and the type of ethical dilemma faced.

\section{Insert Table 1}

\section{Health Centers and Hospitals}

Healthcare is the area of social work intervention with the highest recorded number of characteristic ethical dilemmas related to patient confidentiality. There are studies and research in this regard (Goldman \& Tabak, 2010; Greene \& Kulper, 1990; Kadushin \& Egan, 2001; Proctor, Morrow-Howell \& Lott, 1993; Sparks, 2006) in which the most important ethical 
dilemmas are enumerated and analyzed and which agree with the results obtained in the article. So, in all cases $p<0.01^{* *}$. Confidentiality is the right of a person to keep information of a personal character reserved and to decide who, when and what type of professional or other person should be informed, as well as what type of information is revealed.

In the health sector, there are differing points of view as to the protection of patient confidentiality and privacy in relation to advances in technology and patients' rights to information. Information which becomes known to workers for professional reasons and which must remain a secret, leads to ethical dilemmas on a regular basis in the healthcare sector. Besides this, professionals from the healthcare sector have pointed out that they experience difficulties related to the interaction between patients, such as respect for autonomy, and personal relationships or with being truthfully honest.

Respecting patient autonomy is a key aspect of professional intervention. Law 41/2002 on patient autonomy requires healthcare professionals to respect the right of patients to decide and to respect patients' will in regards to questions related to the patients' health and wellbeing which is crucial in the healthcare sector. This is where diagnostic evaluations regarding a patient's capacity to made their own decisions and their legal competency comes into play, as well as the autonomy of the healthcare worker themselves. All these aspects are relevant when undertaking or managing any type of professional intervention in the healthcare sector and it is here that ethical dilemmas emerge. Finally, it is important not to forget that "the ethical climate influences both decision-making and subsequent behavior responses to ethical dilemmas" (Goldman \& Tabak, 2010, p.233). 


\section{Children}

In regards to social intervention with minors, the duration of the intervention appears in first place on the list of characteristic ethical dilemmas. Forty-five-point three percent of the professionals noted dilemmas of this type versus $30.1 \%$ of the rest of the workers. These results agree with Meysen and Kelly (2018) who conducted a comparative study between Portugal, England / Wales, Slovenia and Germany, where they point out that the scarcity of resources is clearly influencing a worse attention to children: "professionals in Portugal reflected not only on the precarious conditions of families but also the lack of financial and human resources in institutions like schools and hospitals" (p.4).

Social workers have to study and assess the environment in which the minor(s) in question live(s), issuing reports and expert opinions in order to keep everyone implicated in the intervention informed of the necessary measures and proposals. The characteristic ethical dilemmas are related to drawing up reports on the patients $(42.6 \%)$ and legal assistance (19.8\%). In relation to the above, ethical dilemmas regarding confidentiality and disclosing information related to someone's social history are also apparent. Respectively, $50.6 \%$ and $41.4 \%$ of professionals noted difficulties in relation to these aspects.

The best interest of the minor is a critical aspect that irremediably leads to conditions of asymmetry in certain situations between the professional and the subject of the intervention. The vulnerability of minors places the social worker in an unexpected situation of power which exposes them to the risk of engaging in paternal behaviors. This is where ethical dilemmas distinctive of this occupational sector in terms of personal relationships with the beneficiary. Forty-six-point eight percent of professionals noted that they often experience dilemmas of this type versus $26.4 \%$ of the remaining professionals. 
Finally, ethical dilemmas related to the duty to inform a third party were reportedly faced by social workers from this area. Cases involving children often imply complex decision making related to the ownership of information and the need to inform teachers or guardians of certain dangerous behaviors.

\section{Immigrants}

This area of intervention has become a space for professional intervention which is particularly relevant due to the high migratory flow into Spain over the last two decades. The majority of tasks undertaken by social workers in this area are aimed at covering the basic needs of migrants, informing them of their rights and provided the appropriate resources for each situation, as well as processing important documentation in order for the migrants to obtain legal residency in the country.

In this context, the characteristic ethical problems noted include the duration of the intervention (45.6\%) and the distribution of available resources (44.8\%). State intervention related to migrants requires a more interim dedication mainly due to linguistic and cultural factors, the need to establish a relationship based on mutual trust and the need to provide affectionate and emotional support, by creating spaces and strategies for migrants to achieve autonomy and effective integration, for example. Similarly, it is not surprising that resources and their distribution generate ethical dilemmas in a time of economic crisis. These results agree with Mänttäri-van der Kuip (2016): "the experiences of increasing budget constraints, increasing work overload and the effect on one's work of insufficient resources on the part of collaborating service providers were all statistically significant predictors of reactive moral distress" (p. 92).

Processing documentation tends to be the resource which is in most demand and the provision of legal assistance is also a common necessity for social workers. Legal proceedings dealing with 
the stay or deportation of immigrants is another area in which ethical dilemmas emerge (19.1\% versus $9.7 \%$ of the remaining professionals). Finally, and similarly to the previous sector, confidentiality and the need to pass on personal information are also ethical dilemmas experienced by social workers in this area of intervention, especially when the authorities (police, immigration services, judges) request information from the institutions who work in this sector: "providing information to legal agencies to comply with one set of immigration laws may actually lead social workers to break laws governing confidentiality" (Furman, Ackerman, Loya, Jones \& Egi, 2012, p.179).

\section{Women}

Aside from public social services mandated to work with women, there are other types of services mandated to provide a more specialized service. This type of intervention is often related to situations of discrimination and above all issues of gender violence (Cervantes, 1993; Lindhorst, Macy \& Nurius, 2005; Wiech, 2009). In this context, the ethical dilemmas experienced by social workers are again related to confidentiality and the question of whether to reveal personal information or information related to the beneficiary's social history. Further, "ethical dilemmas are an inevitable part of working with women and families experiencing domestic violence" (Wiech, 2009, p.66).

Social workers in this area often find themselves legally obliged to denounce abuse or discrimination. In many cases, these situations lead to ethical difficulties in regards to what aspects of someone's social history and personal information should be revealed and to whom, because it is detrimental to the safety of women and their children, if they had them. The data shows that social workers often find themselves in the dilemma of whether to facilitate personal information: $41.4 \%$ versus $27.8 \%$ of the remaining professionals. The same goes for the issue of 
whether to facilitate information relating to someone's social history: $37.1 \%$ versus $27.4 \%$ of social workers from other areas of intervention.

Dilemmas related to autonomy, specifically in relation to making decisions on behalf of the service user regarding the question of whether to denounce discrimination, abuse or violence are most apparent in this area. The ethical dilemma lies between the professional's obligation to respect the autonomy of the service user and the legal obligation to communicate and act when faced with situations of discrimination and/or abuse. This was specifically noted by $49.2 \%$ of social workers from this area versus $35.9 \%$ of social workers from other areas of intervention. These data agree with the conclusions of the focus groups conducted by Wiech with social workers:

from both groups expressed diverging views about when beneficence and a duty to protect should supersede a client's expressed wishes. Since self-determination was the anchoring focus of the Group A discussion, participants were generally hesitant to overstep a client's wishes and call the police. (Wiech, 2009, p.53)

Legal assistance is another area in which ethical dilemmas emerge as the social worker can be quoted as an expert witness. This can cause technical difficulties is assessing and evaluating risks adequately, the fear of being held legally responsible, the level of detail of the information provided, etc. Finally, ethical dilemmas related to the duration of a particular intervention were also noted in relation to the limited time dedicated to each case. This was highlighted by $43 \%$ of social workers working with women against $34 \%$ of social workers from other areas of intervention. 


\section{Family}

Social intervention with families is one of the areas with the longest tradition in social work. Social workers working with families deal with two types of intervention: direct and indirect, where a series of ethical dilemmas emerge. In regards to indirect intervention, which has to do with the mobilization of resources and involving other professionals working with families, the ethical dilemmas that emerge include confidentiality ( $45 \%$ versus $34 \%$ of social workers from other areas of intervention), disclosing personal information (35\% versus $23.7 \%$ of social workers from other areas and drawing up reports.

Direct intervention is relationship-based social work undertaken with different members of a family by way of providing support, information, educational support and through confrontation. With direct contact with families and family members, the most significantly represented ethical dilemmas emerge in the interactions between beneficiaries and social workers in relation to "personal relationships". When social workers work with families,

often hear stories that can "break one's heart," or cause one to be inadvertently "sympathetic vs. empathetic" to the clients' experiences and/or pain. Many of our clients have been subjected to abuse, neglect, or other forms of violence or maltreatment. Some report stories of abandonment, domestic violence, emotional abuse, or other wrenching experiences. Some even report having difficulty with intimacy as a result of their reported pain. When social workers have not clearly identified and/or managed their emotional issues and baggage that they brought into the profession, the scope and nature of client/worker relationships can become quite blurry. Subsequently, instead of helping, the social worker may start the path of hurting the client while disclosing or sharing his or her own personal experiences. (Handon, 2009, p.1) 
It is affirmed that there is a greater predominance of this type of ethical dilemmas related to "personal relationships" in the field of family intervention. This was described by $32.2 \%$ of social workers in this area versus $22.8 \%$ of social workers from other areas of intervention.

\section{Marginalized homeless people}

Homelessness is an area of social work intervention which relates to all types of social exclusion related to a lack of housing and other the last few years it has grown in relevance in the social work sector due to the high number of people gravely affected by the financial crisis. It is a process which requires continuous professional intervention and support. Intervention in this regard tends to be focused on providing stability, improvement and changes aimed at securing the social integration of these people. This type of intervention also requires interim dedication and a level of commitment which is often not possible and which produces ethical dilemmas. These dilemmas have their origin in the budgetary cuts of the Welfare State and in the change of social policies because of the economic crisis. These changes generate new ethical tensions in social workers and, apparently, to a greater extent in this area of intervention, as stated in previous studies (Banks, 2011; Spijkerboer, van der Stel, Widdershoven \& Molewijk, 2017). Fifty-six and eight tenths percent of social workers from this area referred to this type of dilemma versus $37 \%$ of social workers from other areas of intervention. It is worth bearing in mind that "ethics is not about simple dilemmas, that is choices between two courses of action. Ethical being and action require hard work on the part of social workers" (Banks, 2011, p.19).

The division and distribution of resources also leads to dilemmas. Working with homeless people can lead to ethical dilemmas related to the provision of resources as those who live on the street often refuse to accept the provisions offered. In this regard, ethical dilemmas emerge in 
relation to the juxtaposition between the need to intervene and the autonomy of the beneficiary. This idea appears in a recent study with an example of this type of dilemmas:

For example, a client, heavy alcoholic, may have the right to make the autonomous choice to drink himself to death. However, the professional may also feel bound to your professional duty to stimulate the client to recover, get healthy, and stop drinking. How should the professional apply the principle of recovery, especially when it collides with the principle of autonomy? (Spijkerboer, van der Stel, Widdershoven \& Molewijk, 2017, p.3)

The data presented indicate that this type of dilemma appears overrepresented in the intervention with homeless. Precisely $45.5 \%$ of social workers in this area reportedly experienced this type of dilemma versus $35.1 \%$ of social workers from other areas of intervention.

Confidentiality is another characteristic ethical dilemma as this type of social worker comes into contact with a multitude of different professionals which complicates the issue of management and the privacy of the beneficiary's personal information. There is also the mobility of these people which further complicates the question of information management. This was explained by $52 \%$ of social workers who claimed to have experienced this type of ethical difficulty versus $38 \%$ of social workers from other areas of intervention.

Finally, dilemmas related to the incompetence of a fellow social worker and/or professional were apparent here. The frequency of the contact with these beneficiaries with different professionals, who are responsible for dealing with separate problems related to the life and development of these people, leads to problems of coordination between social workers and services and situations of ethical dilemmas. There are $50.3 \%$ of professionals from this area of 
social work mentioned experiencing this type of dilemma on a regular basis versus $40.5 \%$ of social workers from other areas of intervention.

\section{Ethnic minorities}

Minorities are ethnic, religious or linguistic groups and are the most marginalized groups in many societies, being excluded from participating in socioeconomic activities and politics and being frequently faced with obstacles preventing them from expressing their identity. While social work tends to guarantee and comply with principles of protection of identity, freedom from discrimination and effective participation, there are many difficulties in doing so which leads to the emergence of certain ethical conflicts.

Ethical dilemmas related to confidentiality have been noted. Information is a key aspect of social intervention and this is where ethical dilemmas arise in terms of confidentiality and the disclosure of personal information. There were $56.8 \%$ of social workers working with minorities who claimed they had experienced dilemmas related to confidentiality versus $38.7 \%$ of social workers from other areas of intervention and $35.9 \%$ experienced dilemmas related to the disclosure of personal information versus $20.7 \%$ of social workers from other areas.

Dilemmas related to resource management and the duration of intervention are due to the complexities inherent in interventions in contexts of interculturality, where problems and interventions should be structured based on a community perspective and for which a more interim dedication is required. This was noted by $40.6 \%$ of social workers working with minorities versus $32 \%$ of social workers from other areas of intervention.

Interventions in this context require the mobilization of different services and resources which are not considered to be necessary by the communities which are the subjects of the intervention. This is so, because resources have to be accommodated to cultural needs and that is often 
complex (Pergert, Ekblad, Enskär \& Biörk, 2008). In the same sense, Van Keer, Deschepper, Francke, Huyghens, and Bilsen (2015) state that "conflicts were basically related to differences in participants' views on what constitutes 'good care' based on different care approaches" (p.9).

Cultural differences mean that, sometimes, beneficiaries do not commit to the initiatives for changes proposed to them by the relevant professionals which allows for the emergence of ethical dilemmas. The adequate use of the available resources causes ethical dilemmas for these professionals. This was stated by $44.4 \%$ of the social workers from this area versus $32.3 \%$ of other social workers.

\section{Youth}

Banks says, rightly, that "youth work is full of ethical tensions and dilemmas" but "little has been written specifically on ethics and youth work" as can be seen in this case study:

While out on a trip with a group of young people. I [a female youth worker] saw one of the participants, a young woman, stealing sweets from a shop. Nobody else seemed to have notice. The young woman had recently returned to the youth club following a long absence and her behavior was often challenging. I felt I was just beginning to develop a relationship of trust with her, and therefore decided not to mention the theft. Afterwards I wondered if I had done the right thing: by not mentioning the incident, I was condoning the theft and passing on the value that it was acceptable. (Banks, 2012, p.3-4)

That is why it is an area of special interest to observe the ethical dilemmas that occur in this area of intervention. Social interventions directed at young people are carried out in a context of conflict, generally speaking, and/or related to difficulties in social and employment-related integration. Interventions are preventative, assistance-based, therapeutic or rehabilitating. In general, the interventions are structured around the social context of the young person in 
question in order for the young person to avoid difficulties in adapting to new contexts and in order to provide the adequate setting for the young person to develop alternative behaviors other than conflict by creating positive experiences which help them to develop appropriate behaviors and which facilitate their reintegration.

The intervention undertaken, both with young people and in related areas such as with families and groups of young people, is very close and leads to the emergence of ethical dilemmas related to personal relationships with the beneficiary. Thirty-seven percent of social workers from this area state that they have experienced dilemmas of this kind versus $26.4 \%$ of social workers from other areas of intervention.

This type of intervention is usually carried out in the context of young people involved in social conflict where legal assistance is required on the part of the professionals in legal proceedings and which leads to ethical dilemmas. Twenty-five-point one percent of respondents said they faced ethical dilemmas related to the provision of legal assistance versus $12.7 \%$ of respondents from other areas of intervention.

\section{Prisoners and former prisoners}

Social work in this area is highly specialized and is based on a situation of deprivation of liberty. This area is especially complex for social workers and there can be various ethical conflicts as Toi (2015) points out: "inevitably, social workers in prisons face value dilemmas, role conflicts, or difficulties in ethical decision-making, due to the philosophical difference between social work and correctional organization" (p.20).

Tasks carried out by professionals in this sector include communicating with prisoners and their families, with a support network and gathering information from those who have co-habited with the subject of the intervention in order to get the most comprehensive information possible. 
The personal information in need of management is extensive in a correctional context and it is not uncommon for dilemmas to emerge that are related to confidentiality, as was confirmed by $50 \%$ of social workers working in this sector. Especially in a work space in which security takes precedence over other considerations and where confidentiality is subordinated to it. This aspect is explained in Baldry \& Sotiri (2009): “one of the key challenges for social workers employed by a correctional department is finding ways to adhere to social work ethics and values within an institution which gives priority to security over other considerations" (p. 369). It is not strange that, in this area, the ethical dilemmas related to confidentiality are mentioned by almost $50 \%$ of professionals in this area. This percentage is more much higher than in other areas.

The importance given to certain crimes or infringements in the media requires professionals to disclose relevant information and it is here that the most commonly represented ethical dilemmas emerge: information disclosed to the media. Sixteen-point six percent of social workers in this area considered this to be a significant dilemma versus only $6.1 \%$ of social workers from other areas of social work intervention.

\section{Elderly people}

In this area, there are several publications that have studied the ethical dilemmas related to older people (Bergeron \& Gray, 2003; Fitting, 1986; Smebye, Kirkevold \& Engedal, 2016). Ethical dilemmas related to autonomy are the most relevant in regards to assistance-based interventions to do with the elderly. The respect to autonomy implies non-interference with the rights, duties and values of the beneficiaries as well as the need to accept the options chosen by the beneficiaries. Only in certain situations of cognitive disability can family members or professionals make decisions on behalf of the elderly person in question. The assessment of 
cognitive ability depends greatly on the person's ability to make decisions on the relevant course of action.

Elderly people often show varying degrees of cognitive disability which leaves the professionals working with them faced with the difficulty of adequately assessing whether the person is or is not competent enough to make decisions regarding their medical treatment or way of life and this is where ethical dilemmas emerge to a significant extent. Autonomy, in the care of the elderly, is frequently in conflict with beneficence (Fitting, 1986). This is where ethical dilemmas appear in a relevant way in this area of intervention. In fact, $53.5 \%$ of social workers in this area stated that they faced this type of dilemma versus $40.8 \%$ of social workers from other areas of intervention.

Dilemmas related to financial or material considerations are also evident here and, sometimes, they tend to be compensated for by certain signs of gratitude for an efficient and professional service. Accepting gifts and presents may be considered harmless, ethically speaking, so long as it does not influence the beneficiary's decision-making ability or lead to any inappropriate discrimination, positive or otherwise. However, the differentiation between hospitality, incentive and manipulation is where ethical conflict emerges among social workers. This issue was raised by $36.2 \%$ of social workers in this area versus $29 \%$ of social workers from other areas of intervention.

Other investigations (Smebye, Kirkevold \& Engedal, 2016) also obtained similar conclusions related to autonomy in patients with dementia and revealed the main dilemmas:

(1) The autonomy of the person with dementia conflicted with the family carer's and professional caregiver's need to prevent harm (non-maleficence); (2) The autonomy of the person with dementia conflicted with the beneficence of family carers and professional 
caregivers; (3) The autonomy of the person with dementia conflicted with the autonomy of the family carer. In order to remain living in their own homes, people with dementia could accept being dependent on others in order to uphold their actual autonomy. (p.11)

\section{Refugees and asylum seekers}

Social work with refugees and asylum seekers has always been a specialized area of intervention due, mainly, to the fact that this group of people is especially vulnerable. Social intervention with refugees' ranges from emergency social assistance (first reception) to programs aimed at their integration and social promotion:

The social workers of the institutions that attend these new groups are often unprepared to deal with both the practical and ethical issues of this raises, and there is no serious or systematic preparation on social work courses or in practice settings. All of these workers are equipped to manage the complex situation of those subject to immigration and the differing needs and entitlements. (Hayes \& Humphries, 2004, p.26)

One of the main obstacles of individualized assistance is the lack of time, as was explained by Barrero,

the lack of time for individualized assistance tends to be another obstacle which we have to fight by establishing priorities, organizing times and dates for visits while keeping up with work meetings of a systematic nature with other social workers dealing with the same cases and by encouraging relationships between refugees in similar circumstances in order to foster a sense of self-help. (Barrero, 1993, p.180)

The statistics confirm that this is an area in which ethical dilemmas emerge, for instance, $54.7 \%$ of social workers working with refugees and asylum seekers state that they have 
experienced ethical dilemmas related to the duration of an intervention versus $40.3 \%$ of social workers from other areas of intervention.

Social workers are familiar with the complex realities the refugees they serve have had to endure and they are often required to obtain information from these groups for the media. The media plays an important role in raising public awareness of the rights of refugees and the situations of vulnerability in which they live, but the media also favors sensationalist news that exposes refugees in reports, photographs and documentaries.

Knowing what type of information to disclose, to whom and for what purpose is crucial. This worry has been expressed as an ethical dilemma of particular relevance for these professionals: $16.5 \%$ of social workers working with refugees and asylum seekers state that they face ethical dilemmas related to passing on information to media outlets versus only $6.9 \%$ of social workers from other areas of intervention.

\section{Educational centers and social and employment integration}

Education has been and still is one of the original areas of social work intervention for the promotion of social wellbeing, for capacity building and to improve the quality of life of people in need. This can be developed in regulated centers for education such as the educational programs aimed at securing social and employment integration for beneficiaries. Firstly, this type of social takes the form of preventative interventions and assistance aimed at dealing with problems such as absenteeism, academic failure, the integration of immigrants and disadvantaged groups, co-habitation and dealing with the phenomenon of violence, etc. In terms of social and employment-related integration, the objective is to facilitate this type of integration of beneficiaries through personalized itineraries for integration, assessment and assistance throughout the process of integration. The activities most commonly carried out by social 
workers in this area consist of guidance programs, individual capacity-building, occupational and professional training, work experience, etc. (Allen-Meares, 2004; Constable, 2002; Dupper, 2003; Openshaw, 2008; Roberts, 1971; Villarreal, 2017).

In social work with already marginalized students, ethical dilemmas are especially difficult (Barret, 2014):

School social work with students already marginalised by the school system could be ethically challenging. Care was needed to "do no harm" (...). Practitioners juggled: "dilemmas, twisting and turning in the wind" (...), with frequent decisions to be made about providing teachers with helpful, perhaps generalised but not confidential information. (p.208) The ethical dilemmas noted here as significant and differentiated from other areas of intervention are mainly related to the incompetence of other professionals (56.4\%) and personal relationships with the beneficiaries $(39.1 \%)$. The first is due to the fact that within the education sector, social workers have to work with a wide range of different professionals in an interdisciplinary manner. Coordinating and cooperating with other professionals is where the ethical dilemmas appear to emerge. The second dilemma is directly related to accompanying beneficiaries in their learning process in which the level of intimacy and the personal nature of the relationship can lead to ethical dilemmas. Reamer (2003) explains that, often, it is necessary to establish and delimit the limits of the professional relationship. This idea is also present in universities:

School social workers' relationships with students should always remain within the context of the social worker's professional abilities. Since students are minors who may not always understand relationship boundaries, the burden is on counselors to act professionally and ethically and explain those boundaries where necessary. (OLLU, 2018) 


\section{Mental health}

The most characteristic ethical dilemma related to mental health is that of autonomy. Social interventions aimed at people with some type of mental illness or disability is complex in terms of assessing the level of real autonomy when it comes to decision making. The main purpose of interventions of this kind is to achieve the highest degree of personal autonomy possible. However, in this juxtaposition between the need to assess and the aim to protect the autonomy of the beneficiary, the social worker often finds themselves apprehended and required to make decisions which can lead to dilemmas related to the level of personal autonomy of the beneficiary. A good example can be seen when the professionals surveyed explain

that they sometimes identified basic principles and that they tried to weigh different principles against one another (...) So, what is it we should emphasize, should we in a way emphasize safety and the risk principle, or should we in a way emphasize the being-able-to-grow principle and autonomy so the patient can actually have a chance at self-development. Some said they attempt to find a balance between the legal and the ethical. (Molewijk, Hem \& Pedersen, 2015, p.5)

These ethical tensions are more common in this area. Fifty-one-point one percent of social workers from this area stated that they have experienced this type of dilemma versus only $35.7 \%$ of social workers from other areas of intervention.

\section{Disability}

The main dilemma faced by professionals in this area of intervention, as was the case with mental health, is that of the autonomy of the beneficiary. Fifty-one-point nine percent of professionals mentioned this dilemma as typical of this area of intervention. This data is 
consistent with the statements made in previous studies on the degree of user competence as a source of ethical dilemmas (Donat 2005; Iacono \& Murray, 2003; Wilkins 2012).

The resolution of ethical dilemmas in this area can be approached from a broader perspective, as proposed by Wilkins (2012): "One positive way forward for social workers facing these dilemmas might be to try and ascertain what ethical positions other individuals are taking and thereby, gaining an improved understanding of their actions and priorities" (p.104).

\section{Drug dependency}

Social intervention related to drug addiction is another area in which social workers are required to collaborate with other professionals to develop preventative and interventionist strategies, both in terms community-based preventative programs and direct intervention carried out by specialized service providers. The need to collaborate with different professionals is due to the complexity of the problem of drug addiction and this is where ethical dilemmas related to the incompetence of other professionals appears to be commonplace.

Galvani \& Forrester (2011) point out that social workers are poorly trained to work in this field. In the conclusions of his article they state:

Gaps in the preparation of social workers for working with people with alcohol and drug problems have been identified for more than 30 years and yet have consistently been overlooked or ignored (...) It is clear from both the survey and the qualitative responses that front-line social workers are regularly dealing with the problem's substance use presents to people in touch with social work services without the knowledge or confidence to respond appropriately. (p.437) 


\section{Limitations of the investigation}

The study is not without limitations. Obviously, the research has two clear limitations: first, the space in which it is developed (a single country, Spain) and, second, a limitation in the deepening in each of the areas of intervention studied, but it is also appropriate to emphasize that the research opens new opportunities for detailed study in each of them.

\section{Conclusion}

The article has identified the main dilemmas faced by social workers in Spain depending on the specific area of intervention and is the first time a study of this kind has been carried out in Spain whereby the work of professional social workers is divided into the different areas of intervention and the ethical dilemmas are localized, as proposed in the research hypotheses. These are the most significant results obtained from the investigation:

a) The typology of the ethical dilemmas faced in the 15 identified areas of intervention has been analyzed and common dilemmas related to health, children, immigration, women, families, marginalized people, ethnic minorities, prisoners and the elderly have been established.

b) The most pertinent ethical dilemmas are found in the healthcare sector (confidentiality, disclosure of personal information and patient autonomy). The Organic Law 15/1999 on data protection and Law 41/2002 on patient autonomy have led to advancements but issues still remain. Besides confidentiality, dilemmas related to the disclosure of information related to a patient's social history, the need to inform third parties and the issue of informed consent are the reasons for which this group of professionals requires further assistance in implementing these laws.

c) In regards to social work with young people, besides the dilemmas related to whether or not a teacher or guardian should be informed, other dilemmas related to the personal relationships 
established between the social workers and the beneficiaries are also pertinent. This last type of dilemma is also pertinent to interventions with families.

d) Both in the case of working with young people, as with working with marginalized homeless people, ethnic minorities, refugees and asylum seekers, the duration of any given intervention is also a pertinent dilemma. In regards to working with young people, this may be due to the time it takes to carry out a diagnosis and to establish a relationship, while in other cases it may be explained by the fact that resources are not always readily available and that detailed and exhaustive information is required in relation to rights, obligations, specific requirements, resources for social and employment-related integration and housing, etc.

e) Dilemmas related to the disclosure of social history and personal information of beneficiaries and whether or not to facilitate this information are most pertinent to working with women, especially in cases of gender-based violence. Professionals from this sector frequently argue over the juxtaposition between the respect for the women's autonomy and the obligation to denounce such violence and/or abuse.

f) Dilemmas related to the respect for autonomy also appear to be pertinent to interventions in mental health, with disabled persons and the elderly, especially in regards to the assessment of the level of competence of beneficiaries in making decisions about their own lives.

Ultimately, it is concluded that, according to the first hypothesis proposed, there is a correlation between the area of professional intervention and the type of ethical dilemmas that are faced. Although there are many types of dilemmas (confidentiality, autonomy, disclosure of information...) that emerge in various areas of intervention (confirming the second hypothesis), there is a concrete specificity of ethical dilemmas that varies according to the area of intervention. 
These dilemmas must be analyzed and studied in depth to improve ethical decision-making in the different areas of professional intervention. The results may be of special interest to the ethical committees that exist or that may be formed in the future of Social Work. The findings help to better understand and to situate the importance of some ethical dilemmas in certain professional areas of Social Work.

The results allow to underline the importance of a good ethical training of social workers. But not only this, the results indicate that a deeper reflection must be carried out. The university education of the social workers is basic and the professional work needs specialized knowledge of the ethical dilemmas that the professionals in the different areas of specialization must face in order to be more effective and efficient.

\section{References}

Ain, E. J. (2003). Ethical dilemmas of New York City social workers. Michigan: Ann Arbor.

Allen-Meares, P. (Ed.). (2004). Social work services in schools. Boston, Massachusetts: Allyn \& Bacon.

Appelbaum, S. H., Deguire, K. J., \& Lay, M. (2005). The relationship of ethical climate to deviant workplace behavior. Corporate Governance, 5(4), 43-55. doi: $10.18 / 14720700510616587$

Ballestero, A., Úriz, M.J., \& Viscarret, J.J. (2012). Dilemas éticos de las trabajadoras y trabajadores sociales en España. Papers: revista de sociología, 97(4), 875-898. doi:10.5565/rev/papers/v97n4.283

Ballestero, A., Úriz, M.J., \& Viscarret, J.J. (2013). Cuestiones éticas y tipologías de comportamiento ético en la intervención profesional del trabajo social. RES. Revista Española de Sociología, 19, 67-92. 
Ballestero, A., Viscarret, J.J., \& Úriz, M.J. (2013). Funciones profesionales de los trabajadores sociales en España. Cuadernos de trabajo social, 26(1), 127-138. doi:10.5209/ rev_CUTS.2013.v26.n1.41664

Baldry, E., \& Sotiri, M. (2009). Social work in corrections. In P. Swain \& S. Rice (Eds.), In the shadow of the law (pp. 360-275). Melbourne, Australia: Federation Press.

Banks, S. (2011). Ethics in an age of austerity: Social work and the evolving new public management. Journal of Social Intervention, 20(2), 5-23. doi: 10.18352/jsi.260

Banks, S. (Ed.). (2012). Ethical issues in youth work, New York: Routledge.

Barrero, A. M. (1993). Una propuesta metodológica para el trabajo social con refugiados. Cuadernos de Trabajo Social, 6, 167-180. Retrieved from http://cort.as/-9T74

Barret, C. A. (2014). School Social Work in the State of Victoria, Australia.

65 years of student wellbeing and learning support (Dissertation for the degree of $\mathrm{PhD}$ ). University of Melbourne, Melbourne, Australia.

Bégat, I., Ellefsen, B., \& Severinsson, E. (2005). Nurses' satisfaction with their work environment and the outcomes of clinical nursing supervision on nurses' experiences of wellbeing. A Norwegian study. Journal of Nursing Management, 13(3), 221-230. doi: 10.1111/j.1365-2834.2004.00527.x

Bergeron, L. R., \& Gray, B. (2003). Ethical dilemmas of reporting suspected elder abuse. Social Work, 48(1), 96-105. doi: 10.1093/sw/48.1.96

Cervantes, N. N. (1993). Therapist duty in domestic violence cases: Ethical consideration. In M. Hansen \& M. Harway (Eds.), Battering and family therapy. A feminist perspective (pp. 147155). Newbury Park: Sage Publications. 
Constable, R. T. (Ed.). (2002). School social work: Practice, policy, and research perspectives. Chicago: Lyceum Books.

Corley, M. C., Minick, P., Elswick, R. K., \& Jacobs, M. (2005). Nurse moral distress and ethical work environment. Nursing Ethics, 12(4), 381-390. doi: 10.1191/0969733005ne809oa

Donat, D. C. (2005). Encouraging alternatives to seclusion, restraint, and reliance on PRN drugs in a public psychiatric hospital. Psychiatric Services, 56(9): 1105-1108. doi: 10.1176/appi.ps.56.9.1105

Dulmus, C. N., \& Sowers, K. M. (Eds.). (2012). The profession of social work: Guided by history, led by evidence. New York: John Wiley \& Sons.

Dupper, D. (2003). School social work: Skills and interventions for effective practice. Hoboken, New Jersey: John Wiley.

Fitting, M. D. (1986). Ethical dilemmas in counseling elderly adults. Journal of Counseling \& Development, 64(5), 325-327. doi:10.1002/j.1556-6676.1986.tb01123.x

Førde, R., \& Aasland, O. G. (2008). Moral distress among Norwegian doctors. Journal of Medical Ethics, 34(7), 521-525. doi: 10.1136/jme.2007.021246

Furman, N., Ackerman, A. R., Loya, M., Jones, S., \& Egi, N. (2012). The criminalization of immigration: Value conflicts for the social work profession. Journal of Sociology \& Social Welfare, 39(1), 169-185. Retrieved from http://cort.as/-9T7G

Galvani, S., \& Forrester, D. (2011). How well prepared are newly qualified social workers for working with substance use issues? Findings from a national survey in England, Social Work Education, 30(4), 422-439. doi: 10.1080/02615479.2010.504981 
Goldman, A., \& Tabak, N. (2010). Perception of ethical climate and its relationship to nurses’ demographic characteristics and job satisfaction. Nursing Ethics, 17(2), 233-246. doi: $10.1177 / 0969733009352048$

Gómez, R., Alonso, M., \& Llamazares, M.L. (2018). Factorial validity of the Maslach Burnout Inventory-Human Services Survey (MBI-HSS) in a simple of Spanish social workers. Journal of Social Services Research. doi: 10.1080/01488376.2018.1480549

Greene, G. J., \& Kulper, T. (1990). Autonomy and professional activities of social workers in hospital and primary health care settings. Health \& Social Work, 15(1), 38-44. doi:10.1093/hsw/15.1.38

Häggström, E., Mbusa, E., \& Wadensten, B. (2008). Nurses' workplace distress and ethical dilemmas in Tanzanian health care. Nursing Ethics, 15(4), 478-491. doi:

\section{$10.1177 / 0969733008090519$}

Handon, R. (2009). Client relationships and ethical boundaries for social workers in child welfare. The New Social Worker, 16, 1. Retrieved from http://cort.as/-9T7W

Hayes, D., \& Humphries, B. (Eds.). (2004). Social work, immigration and asylum: Debates, dilemmas and ethical issues for social work and social care, London: Jessica Kingsley Press.

Hofmeyer, A. (2003). A moral imperative to improve the quality of work-life for nurses: building inclusive social capital capacity. Contemporary nurse: A journal for the Australian nursing profession, 15(1-2), 9-19. doi: 10.5172/conu.15.1-2.9

Iacono, T., \& Murray, V. (2003). Issues of informed consent in conducting medical research involving people with intellectual disability. Journal of Applied Research in Intellectual Disabilities, 16(1), 41-51. doi: 10.1046/j.1468-3148.2003.00141.x 
Kadushin, G., \& Egan, M. (2001). Ethical dilemmas in home health care: A social work perspective. Health \& Social Work, 26(3), 136-149. doi: 10.1093/hsw/26.3.136

Law 41/2002, of 15 November, regulating patient autonomy and rights and obligations of information and clinical documentation. Boletín Oficial del Estado, 274, 40126-40132. Retrieved from http://cort.as/-9T7d

Lindhorst, T., Macy, R., \& Nurius, P. (2005). Contextualized assessment with battered women: Strategic safety planning to cope with multiple harms. Journal of Social Work Education, 41(2), 331-352. Retrieved from http://cort.as/-9T7f

Mänttäri-van der Kuip, M. (2016). Moral distress among social workers. International Journal of Social Welfare, 25(1), 86-97. doi:10.1111/ijsw.12163

Meysen, T., \& Kelly, L. (2018). Child protection systems between professional cooperation and trustful relationships: A comparison of professional practical and ethical dilemmas in England / Wales, Germany, Portugal, and Slovenia. Child \& Family Social Work, 23(2), 222-229. doi: $10.1111 /$ cfs. 12403

Molewijk, B., Hem, M. H., \& Pedersen, R. (2015). Dealing with ethical challenges: a focus group study with professionals in mental health care. BMC Medical Ethics, 16(4), 1-12. doi: $10.1186 / 1472-6939-16-4$

OLLU (Our Lady of the Lake University). (2018). A look at ethical issues in school counseling. San Antonio, Texas: OLLU. Retrieved from http://cort.as/-9T7i

Openshaw, L. (2008). Social work in schools: Principles and practice. New York: Guildford Press. 
Organic Law 15/1999, of December 13th, Protection of Personal Data. Boletín Oficial del Estado, 298, 43088-43099. Retrieved from http://cort.as/-9T7n

Pergert, P., Ekblad, S., Enskär, K., \& Björk, O. (2008). Bridging obstacles to transcultural caring relationships-tools discovered through interviews with staff in pediatric oncology care. European Journal of Oncology Nursing, 12(1), 35-43. doi: 10.1016/j.ejon.2007.07.006

Proctor, E.K., Morrow-Howell, N., \& Lott, C.L. (1993). Classification and correlates of ethical dilemmas in hospital social work. Social Work, 38(2), 166-177. Retrieved from http://cort.as/9T7v

Rathert, C., May, D. R., \& Chung, H. S. (2016). Nurse moral distress: A survey identifying predictors and potential interventions. International Journal of Nursing Studies, 53(1), 39-49. doi: 10.1016/j.ijnurstu.2015.10.007

Reamer, F. (2003). Boundary issues in social work: Managing dual relationships. Social Work, 48(1), 121-133. doi: 10.1093/sw/48.1.121

Roberts, R. (1971). The role of the school social worker. Australian Social Work, 24(2), 24-27. doi: $10.1080 / 03124077108549323$

Rushton, C. H., Kaszniak, A. W., \& Halifax, J. S. (2013). A framework for understanding moral distress among palliative care clinicians. Journal of Palliative Medicine, 16(9), 1074-1079. doi: 10.1089/jpm.2012.0490

Sales, B. D., \& Folkman, S. (2000). Ethics in research with human participants. Washington: American Psychological Association. 
Smebye, K.L., Kirkevold, M., \& Engedal, K. (2016). Ethical dilemmas concerning autonomy when persons with dementia wish to live at home: A qualitative, hermeneutic study. $B M C$ Health Services Research, 16:21. doi: 10.1186/s12913-015-1217-1

Sparks, J. (2006). Ethics and social work in health care. In S. Gehlert \& T. A. Browne (Eds.), Handbook of health and social work (pp. 43-69). Hoboken, New Jersey: John Wiley \& Sons.

Spijkerboer, R. P., van der Stel, J. C., Widdershoven, G. A. M., \& Molewijk, A. C. (2017). Does moral case deliberation help professionals in care for the homeless in dealing with their dilemmas? A mixed-methods responsive study. HEC Forum, 29(1), 21-41. doi:

$10.1007 / \mathrm{s} 10730-016-9310-3$

Toi, H. (2015). Professional values and conflict among social workers in prisons: An examination of role stress, strain, and job satisfaction in working with inmates with mental illness and/or substance use disorders. (Dissertation for the degree of $\mathrm{PhD}$ ). University of Connecticut, Connecticut, USA.

Úriz, M.J., Ballestero, A., \& Urien, B. (2007). Dilemas éticos en la intervención social: una perspectiva profesional desde el Trabajo Social, Zaragoza: Mira Editores.

Van Keer, R. L., Deschepper, R., Francke, A. L., Huyghens, L., \& Bilsen, J. (2015). Conflicts between healthcare professionals and families of a multi-ethnic patient population during critical care: An ethnographic study. Critical Care, 19, 441. doi:10.1186/s13054-015-1158-4

Vázquez, O. (2005). Libro blanco. Título de grado en trabajo social. Madrid: Aneca. Retrieved from http://cort.as/-9T81

Villarreal, L., Cox, T., \& Álvarez, M. (Eds.). (2017). School social work: National perspectives on practice in schools. New York: Oxford University Press. 
Wadensten, B., Wenneberg, S., Silén, M., Tang, P. F., \& Ahlström, G. (2008). A cross-cultural comparison of nurses' ethical concerns. Nursing Ethics, 15(6), 745-760. doi:

$10.1177 / 0969733008095385$

Wiech, J. F. (2009). How social workers resolve the ethical dilemmas that arise when working with women experiencing domestic violence (Project for the degree of Master of Social Work). Smith College School for Social Work, Northampton, Massachusetts, USA.

Wilkins, D. (2012). Ethical dilemmas in social work practice with disabled people: Young adults with autism. Ethics and Social Welfare, 6(1), 97-105. doi: 10.1080/17496535.2012.651892 
Table 1

Results obtained, area of intervention and ethical dilemmas. $\chi^{2}$ (Chi squared)

\begin{tabular}{|c|c|c|c|}
\hline \multirow[b]{2}{*}{ Areas of intervention } & \multirow[b]{2}{*}{$p$} & \multicolumn{2}{|c|}{$\begin{array}{l}\text { Type of professional } \\
\text { according to their position }\end{array}$} \\
\hline & & $\begin{array}{c}\text { Works } \\
\text { in the area }(\%)\end{array}$ & $\begin{array}{l}\text { Does not work } \\
\text { in the area }(\%)\end{array}$ \\
\hline \multicolumn{4}{|l|}{ Healthcare Centers and Hospitals } \\
\hline Confidentiality & 0.000 & 52.9 & 37.5 \\
\hline Patient autonomy & 0.003 & 53.3 & 42.4 \\
\hline Disclosure of patient's social history & 0.003 & 37.8 & 27.7 \\
\hline Personal relationships with the patients & 0.005 & 36.6 & 23.9 \\
\hline Informed consent & 0.009 & 36.7 & 27.5 \\
\hline Duty to inform a third party & 0.011 & 52.3 & 44.5 \\
\hline Telling the truth, not the whole truth or lying & 0.018 & 43.3 & 32.3 \\
\hline \multicolumn{4}{|l|}{ Children } \\
\hline Duration of the intervention & 0.000 & 45.3 & 30.1 \\
\hline Legal assistance & 0.000 & 22.7 & 10.2 \\
\hline Writing reports & 0.000 & 42.1 & 31.3 \\
\hline Confidentiality & 0.001 & 50.6 & 36.6 \\
\hline Disclosure of beneficiary's social history & 0.001 & 41.3 & 25.4 \\
\hline Personal relationships with the patients & 0.009 & 46.8 & 26.4 \\
\hline Duty to inform a third party & 0.019 & 53.4 & 44.2 \\
\hline \multicolumn{4}{|l|}{ Immigrants } \\
\hline Duration of the intervention & 0.000 & 45.6 & 34.7 \\
\hline Distribution of available resources & 0.000 & 44.8 & 29.3 \\
\hline Legal assistance & 0.000 & 19.1 & 9.7 \\
\hline Disclosure of beneficiary's social history & 0.001 & 36.5 & 26.4 \\
\hline Confidentiality & 0.027 & 47.8 & 35.7 \\
\hline \multicolumn{4}{|l|}{ Women } \\
\hline Providing phone numbers, addresses, etc. & 0.002 & 41.4 & 27.8 \\
\hline Disclosure of beneficiary's social history & 0.003 & 37.1 & 27.4 \\
\hline Autonomy of the beneficiary & 0.004 & 49.2 & 35.9 \\
\hline Legal assistance & 0.017 & 17.4 & 8.2 \\
\hline Duration of the intervention & 0.019 & 43.0 & 34.0 \\
\hline \multicolumn{4}{|l|}{ Family } \\
\hline Personal relationships with the beneficiaries & 0.009 & 32.2 & 22.8 \\
\hline Confidentiality & 0.003 & 45.5 & 34.0 \\
\hline Disclosure of information & 0.002 & 34.9 & 23.7 \\
\hline Writing reports & 0.009 & 38.6 & 28.6 \\
\hline \multicolumn{4}{|l|}{ Marginalized homeless people } \\
\hline Duration of the intervention & 0.000 & 56.8 & 37.9 \\
\hline Confidentiality & 0.006 & 51.9 & 38.1 \\
\hline Distribution of available resources & 0.005 & 45.5 & 35.1 \\
\hline Incompetence of other professionals & 0.026 & 50.3 & 40.5 \\
\hline \multicolumn{4}{|l|}{ Ethnic minorities } \\
\hline Disclosure of the beneficiary's social history & 0.004 & 33.9 & 20.7 \\
\hline
\end{tabular}


Distribution of available resources

Duration of the intervention

Confidentiality

Young people

Personal relationships with the beneficiary

Legal assistance

Prisoners and former prisoners

Information provided to the media

Confidentiality

Elderly people

Autonomy of the beneficiary

Economic considerations (gifts)

Refugees and asylum seekers

Duration of the intervention

Information provided to the media

Education centers and

social-employment integration

Incompetence of other professionals

Personal relationships with the beneficiary

Mental health

Patient autonomy

Disability

Autonomy of the beneficiary

Drug dependency
$0.013 \quad 44.4$

$0.024 \quad 40.6$

$0.003 \quad 56.8$

$0.009 \quad 36.8$

$0.017 \quad 25.1$

$0.001 \quad 16.6$

$0.003 \quad 49.6$

$0.002 \quad 53.5$

$0.029 \quad 36.2$

0.001

0.001

0.001

0.011

0.016

0.003

0.021

46.2

54.7

16.5

56.4

39.1

39.5

27.1

35.7

51.1

51.9

40.8

40.3

6.9

Incompetence of other professionals

38.4 